Technical Reports

\title{
Polyethylene Pipeline Bending Stresses at an Installation
}

\author{
Anatoly Serebrennikov, Daniil Serebrennikov and Zufar Hakimov
}

Tyumen State Oil and Gas University, Tyumen, Russia

\author{
Article history \\ Received: 19-04-2016 \\ Revised: 23-04-2016 \\ Accepted: 26-04-2016 \\ Corresponding Author: \\ Anatoly Serebrennikov \\ Tyumen State Oil and Gas \\ University, Tyumen, Russia \\ Email: sereb_a_a@mail.ru
}

\begin{abstract}
A polyethylene pipeline trenchless installation with special machines is one of methods of gas pipeline constructions between localities. A polyethylene pipeline is exposed to a short term bend and a significant deformation during an installation. The methods and research results of the polyethylene pipeline ability at the short term bending are presented below. The mathematical model has been created. The analytical calculations of the polyethylene pipeline stress state at the bend have been done and experimentally verified. The requirements have been formulated to ensure the necessary installed pipeline operation properties.
\end{abstract}

Keywords: Trenchless Installation, Polyethylene Pipeline, Deformation Reversibility, Mathematical Model, Stressed State, Strength Characteristics

\section{Introduction}

The economical efficiency, the terrain characteristics and soil conditions, the existing engineering structures on the pipeline path, the climatic conditions and the further pipeline serviceability should be primarily taken in account to choose the pipeline installation method (Antipyev et al., 2002).

The polyethylene pipeline installation methods are based on the specific physical polyethylene properties (plasticity, shock resistance and elasticity) and differed from the metallic pipeline one. In particular, the trenchless installation method based on an elasticity of a polyethylene pipe is widespread. During such method implementation, the pipe-liners and the relevant mechanisms should not create the loads excessing of the limit values and deteriorating of the installed pipeline operation properties (reliability and durability) (Lavrov and Serebrennikov, 2012; Serebrennikov et al., 2012).

\section{The Current Status of the Trenchless Installation Methods Implementation}

The world and Russian companies have a long experience of the polyethylene pipeline installation and operation. At the same time, the significant attention is paid to the improvement of the relevant machines and the production technology.

It is known, in case of absent of the engineering structures and other obstacles on the pipeline path (for example, between the localities) it is advisable to use the special mechanisms (Serebrennikov and Kurochkin, 2003; Ivanov et al., 2003) performing the pipeline installation to the desired depth in the one pass. One of the design solutions implementing this method is shown in Fig. 1.

The wheel trolley is attached to the tractor. The spools (1) with the reeled $100 \mathrm{~mm}$ diameter polyethylene pipe (4) are placed on the wheel trolley. The pipeline due to the tractor pulling force is supplied through the pipeguide (3), located behind the ripper shank (2) and laid to the desired depth. As appropriate the spools are replaced and the pipes are joined.

The polyethylene pipeline is short term bended and significantly deformed and stressed during the installation with this machine.

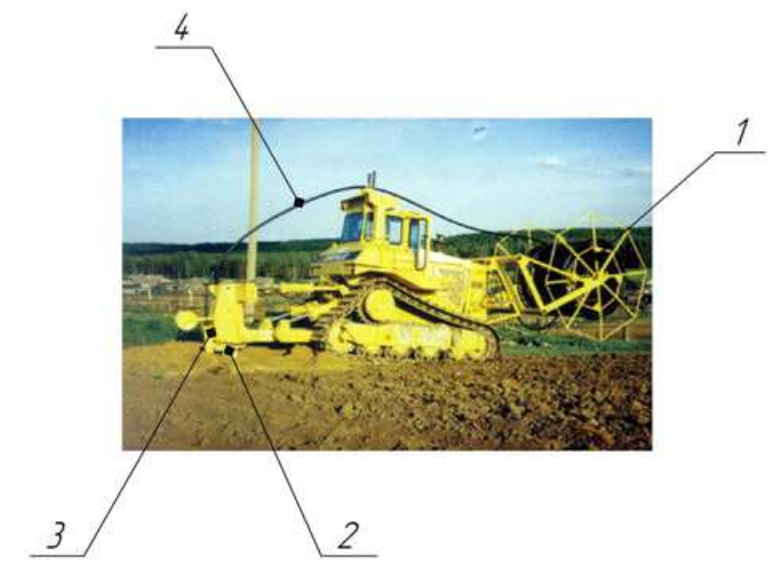

Fig. 1. Scheme of the pipe-layer 
In accordance with the known requirement related to the polyethylene pipe reeled on the spool, the spool diameter should be not less than 20 pipe diameters $\left(D_{\text {spool }}\right.$ $\geq 20 D_{\text {pipe }}$ or $D_{\text {pipe }} / D_{\text {spool }} \leq 5 \%$ ). This requirement ensures that such pipe bending does not affect the strength characteristics of the pipe during the transportation and the storage. So, the pipe will not be deformed after unreeling. However, during pipe-layer design this requirement implementation leads to the significant increasing of the pipe-guide size and, therefore, of the required pulling force.

Thus, it is necessary to research the possibility of the short term pipe bending with the small radius to ensure the required installed pipeline operation properties (reliability and durability). The elastic properties of the pipe material should not be diminished after passing through the pipe-guide. The deformation should be reversible after unloading. Additionally, it is necessary to know the relevant loads to calculate the stresses in the pipe and to determine the tractor pulling force (Serebrennikov and Kurochkin, 2003; Ivanov et al., 2003; Serebrennikov and Khakimov, 2012).

\section{The Personal Research Experience of the Polyethylene Pipe at the Bending}

The experimental pipe-bending device was manufactured to research the strength characteristics of the polyethylene pipe at the bending (Fig. 2).

The pipe-guides of the different radius (2) were bolt jointed (3) to the frame (1). The clams (5) jointed the quick-release support (4) to the frame. The quick-release support fixed the pipe. The curved surfaces of the pipeguide were changed to change the radiuses of the pipe bends corresponding to the real conditions (Serebrennikov, 2004; Serebrennikov and Lavrov, 2005).

The pipe-bending device was installed into the special power plant (Fig. 3), designed to test samples in the certified laboratory of "Sibgazapparat". ("Sibgazapparat" (Tyumen) is one of the biggest polyethylene pipe production enterprises in Russia).

At the first stage the static tests were carried out (Fig. 3a). The polyethylene pipe sample was installed on the pipe-bending device. The one end of sample was fixed to the quick-release support with the clamps. The other end of the sample was attached to the rod of the movable traverse. During the experiment the pipe was bended and pressed to the all pipe-guide surface by the pushing force of the movable traverse. The marks were marked at the equal distances on each sample. The marks indicated the points to measure the deformation along the length of samples. The load measuring system measured the force needed to bend the pipe.

The power plant was stopped when the sample was fully pressed to the all pipe-guide surface. The sample diameters changes were measured at the each mark in 0 ,
2, 5 and $10 \mathrm{~min}$. The maximum test period of the pipe stress $(10 \mathrm{~min})$ exceeded the period of the unexpected stop during the pipe-layer operation many times.

Next, the loading was stopped, the pipe was removed from the pipe-bending device and the pipe diameters were measured at the marks again. The unloaded pipe deflection was measured to indicate the deformation reversibility along the pipe.

All measurements were repeated in $24 \mathrm{~h}$ after unloading in order to evaluate the deformation changes and thereby to evaluate the elastic properties of the pipe in time.

The scheme (Fig. 4) shows that each sample has the $90^{\circ}$ central angle $\left(\mathrm{O}_{1}\right.$ is the center of the circle) after bending and pressing to the pipe-guide with different radiuses $\left(\mathrm{R}_{\mathrm{kp}}\right)$ and has the central angle $(\psi)\left(\mathrm{O}_{2}\right.$ is the center of the new circle) after unloading and straightening up to the new circle with an unknown radius $(\mathrm{R})$.

It was necessary to determine if the sample returned to permissible values of the bend $\left(\mathrm{D}_{\text {pipe }} / \mathrm{D}_{\text {spool }} \leq 5 \%\right)$.

The radius $(\mathrm{R})$ is determined through measuring of the deflection (h) with the formula:

$R=h+R \cdot \cos \psi / 2$

Because the arc length (L) of the bended sample is the same before and after loading $\left(L=R_{k p} \cdot \frac{\pi}{2}=\psi \cdot R\right)$ the central angle $(\psi)$ is determined with the formula:

$\frac{\pi R_{k p}}{2 h}\left(1-\cos \frac{\psi}{2}\right)-\psi=0$

The nonlinear transcendental Equation 2 was solved with the iteration method (Serebrennikov, 2004; Serebrennikov and Lavrov, 2005).

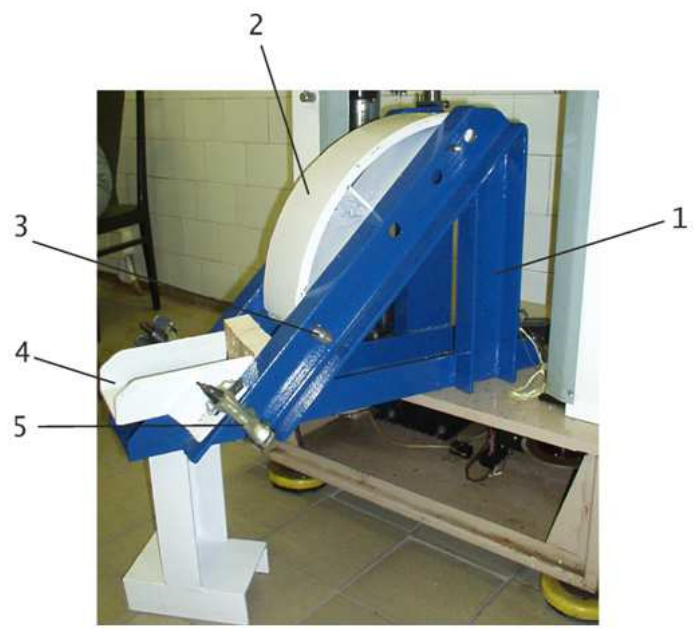

Fig. 2. The experimental pipe-bending device 1-frame 2-pipeguide; 3-bolt joint; 4-quick-release support; 5-clamps 


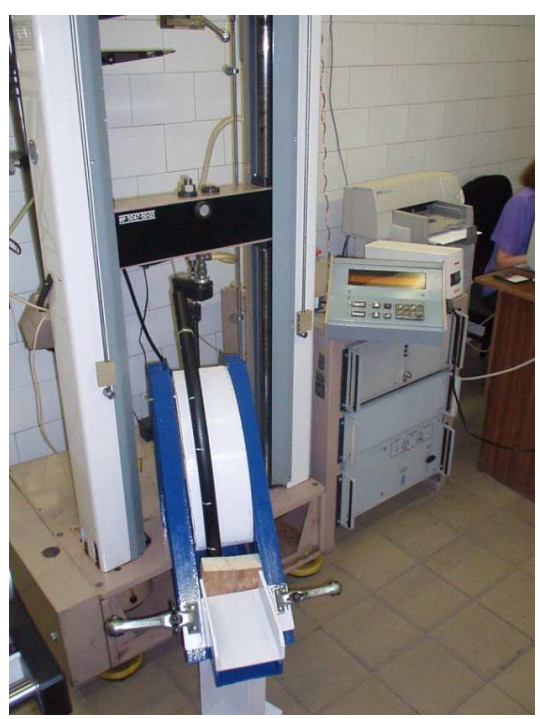

(a)

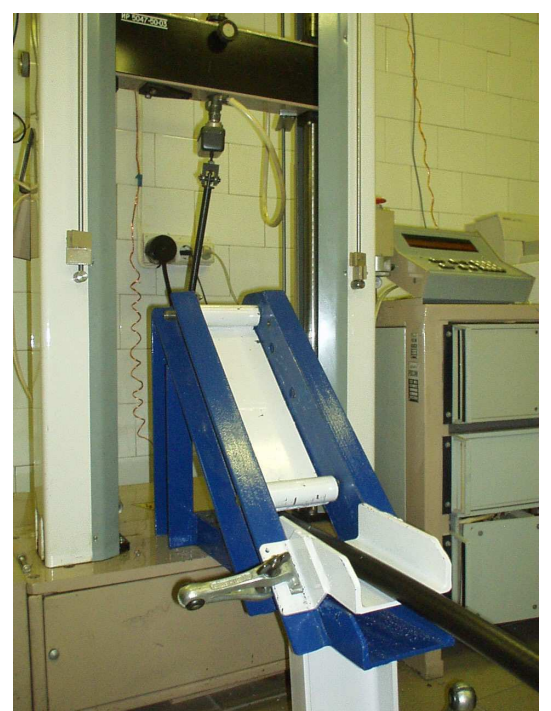

(b)

Fig. 3. Special power plant with the (a) at the static test; (b) at the dynamic test; 1-pipe-bending device; 2-special power plant; 3 movable traverse; 4-load measuring system

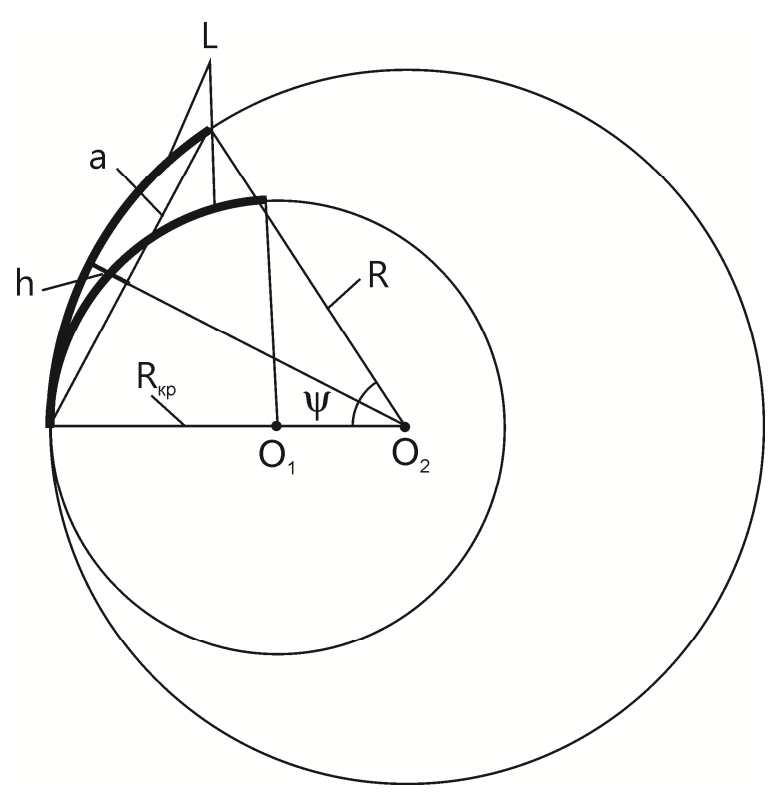

Fig. 4. Scheme of the determination of the sample bend radius after unloading

The determianed central angle $(\psi)$ allowed evaluating the unloaded sample deflection.

The researchers accepted that the deformation reversibility was a criterion of the non-diminution of the physical and mechanical properties after the pipe unloading. The deformation reversibility was verified if:

- The pipe diameter returned to the initial value

- The pipe deflection returned to the ratio: $\mathrm{D}_{\text {pipe }} / \mathrm{D}_{\text {spool }}$ $\leq 5 \%$

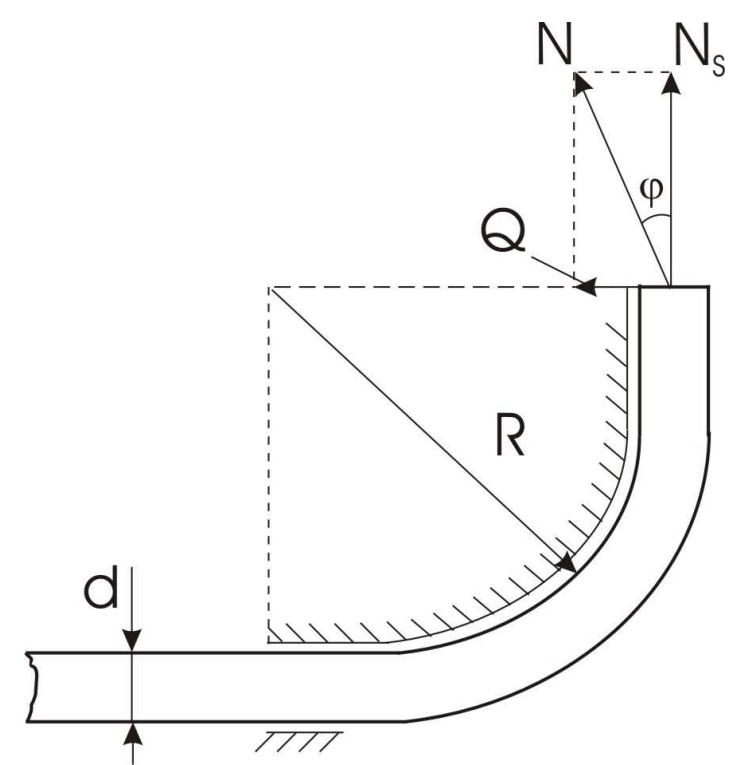

Fig. 5. Scheme of the forces affecting to the bended pipe

At the second stage the dynamic tests were carried out in order to evaluate the deformation reversibility after the sample pulling through the pipe-guide (Fig. $3 \mathrm{~b}$ ). In addition, the force value needed for sample pulling was measured and compared with the static bending force value (Fig. 5).

The pipe-guide was turned in the pipe bending device (Fig. 3b). The one end of the sample was attached to the movable traverse and the sample was pulled through the pipe-guide. The sample diameters and pipe-guide radiuses were changed during the dynamic tests. Force measuring system measured the 
force values needed to pull the polyethylene samples through the pipe-guides. The pulling speed value (150 $\mathrm{m} \mathrm{h}^{-1}$ ) was set basing on the maximum recommended speed for pipe-layer (Serebrennikov, 2004).

The measurement results were processed using statistical methods. The arithmetic average, measurement error and mean square deviation were determined for all measured parameters.

The value of the force in each case allowed determining the value of the bending moment:

$$
M=N_{S}\left(R+\frac{d}{2}\right)+Q\left(R+\frac{d}{2}\right)=N\left(R+\frac{d}{2}\right) \cdot(\cos \phi+\sin \phi)
$$

Further, the arising pipe stresses were calculated with the formula:

$$
\sigma_{s}=\frac{M z}{K J}\left[1-\beta\left(\frac{z}{r}\right)^{2}\right]
$$

Where:

$M=$ bending moment

$z=$ Coordinate of the height of the cross section of the pipe

$K=$ Coefficient of reduction of cross-section rigidity

$J=$ Axial moment of inertia

$\beta=$ Flattening coefficient

$r=$ Outer radius of the test sample

The cross section reducing rigidity coefficient $(\mathrm{K})$ considered the effect of the thin-walled cross-section flattening at the bending on the relation between the bending moment and the curvature change. The coefficient $(\mathrm{K})$ was calculated with the formula:

$$
K=\frac{1+12 \lambda^{2}}{10+12 \lambda^{2}}
$$

\section{$\lambda$ - Geometric pipe coefficient.}

The geometric pipe coefficient $(\lambda)$ was calculated with the formula:

$$
\lambda=\frac{\delta R}{r^{2}}
$$

Where:

$R=$ Radius of the pipe-guide

$r=$ The outer radius of the test sample

The flattening coefficient $(\beta)$ considered the coordinate of the height of the cross section of the pipe (z) about the zero axis. The flattening coefficient $(\beta)$ was defined with the formula:

$$
\beta=\frac{6}{5+6 \lambda^{2}}
$$

The dynamic tests of the samples with the different diameters allowed verifying of the accuracy of the analytical calculations by comparing them with the experimental research results.

The mathematical model and the calculation algorithm have been created to calculate the stresses in the polyethylene pipes of different diameters at the bending. Since the pipe length is much greater than its diameter, the derivation of equations is based on theory of curved rods and curved thin-walled pipes.

The nonlinear properties of the pipe material have been accounted through a variable (secant) modulus $(E c)$ determined with the formula:

$$
E_{c}=\frac{E_{0}}{1+b \sigma_{i n}^{2}}
$$

Where:

$\sigma_{\text {in }}=$ Stress intensity

$E_{0}=$ Instantaneous elasticity modulus

$B=$ Coefficient of dependence of the stiffness versus the deformation

The stress intensity is determined from the formula:

$$
\sigma_{i n}=\sqrt{\left(\sigma^{2}+\sigma_{T}^{2}\right) / 2}
$$

$\sigma=$ Stress along the pipe axis

$\sigma_{T}=$ Radial stresses (They are absent during the pipeline construction, but arising due internal pressure during the gas pumping)

If the annular cross-section curve rod has dS length (Fig. 6), the stress is associated with the bend deformation with the formula:

$$
\sigma=E_{c} \cdot \varepsilon
$$

\section{$E_{c}=$ Secant modulus, МПа}

$E=$ Relative deformation

The relative deformation is a set of the next relative deformations:

- $\quad \varepsilon r-d u e$ to bending the straight pipe

- $\quad \varepsilon s-d u e$ to bending the curved pipe section

- $\quad \varepsilon N$-due to the tensile force $(\mathrm{N})$

- $\varepsilon \mathrm{M}$-due to the bending moment (M) 


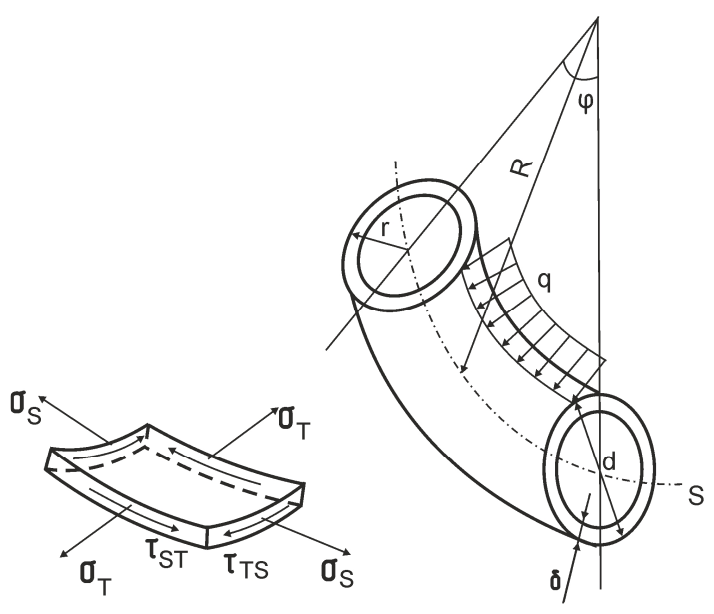

Fig. 6. The stresses acting to the pipe element

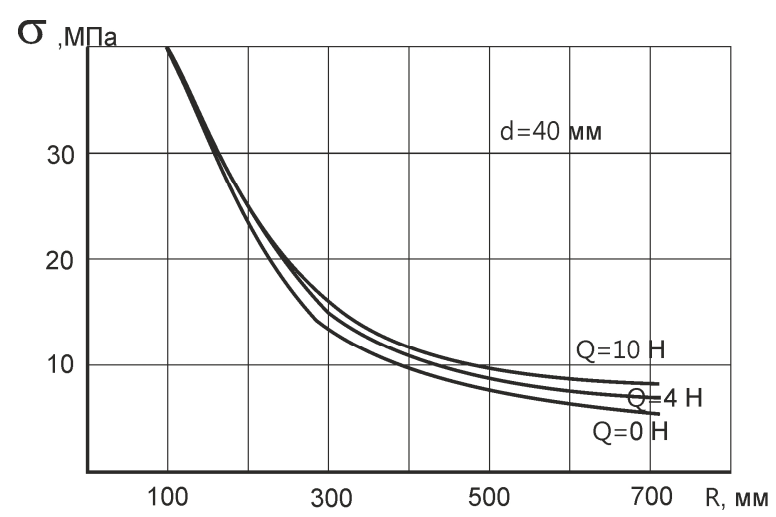

Fig. 7. Pipe stress as function of pipe-guide radius

The specially created PC program allowed to carry out the analytical calculation of polyethylene pipes strength considering the plastic deformations (Serebrennikov, 2004; Serebrennikov and Lavrov, 2005; Lavrov and Serebrennikov, 2008). The analytical calculations results of the standard size pipe are shown in Fig. 7.

The test stress value results (4) were compared to the analytical calculated stress value results (10).

\section{Conclusion}

The possibility of pipe-layer operation, applying a short term polyethylene pipeline bending with above the regulated transportation-storage condition values $\left(D_{\text {spool }}\right.$ $\geq 20 \mathrm{D}_{\text {pipe }}$ or $\mathrm{D}_{\text {pipe }} / \mathrm{D}_{\text {spool }} \leq 5 \%$ ), was proved.

The polyethylene pipe experiments confirmed that the deformation reversibility to the regulated values after the bend loading was the condition to retain the physical and mechanical characteristics of the pipe.

It was found that the required static bending force was not significantly changed during the pipe pulling through the pipe-guide at the given speed. The friction force on the pipe-guide did not exceed $3 \%$ of the pipe pulling force.

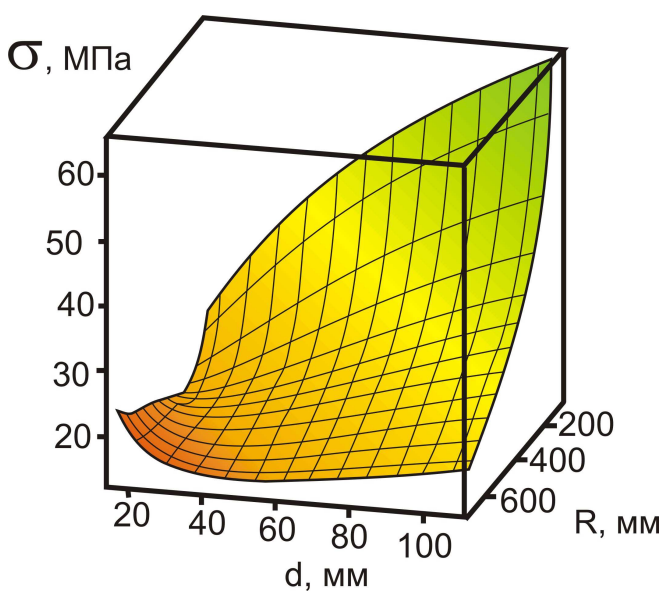

Fig. 8. Pipe stress as function of pipe diameter and pipe-guide radius

A mathematical model was created to carry out the analytical calculations of the stress state of the polyethylene pipeline at bending (Fig. 8).

The polyethylene pipe experiments confirmed that the analytical calculations were correct to calculate the stress values as function of the bending radius and the diameters of the pipe (Serebrennikov et al., 2012).

The experiments were performed at the constant temperature in the laboratory, but the pipe-layer should operate in the cold weather conditions. Thus, the goal of further researches is to identify the elastic properties of polyethylene pipes and to develop the trenchless installation recommendations, depending on the temperature conditions.

\section{Acknowledgement}

Authors gratefully acknowledge the Tyumen State Oil and Gas University (Russia) for the financial support and also the "Sibgazapparat" plant (Russia) for the experiment support.

\section{Author's Contributions}

Anatoly Serebrennikov: Managed the research designed the analytic research method, carried out the result analysis and wrote the manuscript.

Daniil Serebrennikov: Designed the experimental research method, participated in the experiments and he manuscript writing.

Zufar Hakimov: Participated in all experiments and the result processing.

\section{Ethics}

This article is original and contains unpublished material. The corresponding author confirms that all of 
the other authors have read and approved the manuscript and no ethical issues involved.

\section{References}

Antipyev, V.N. G.V. Bakhmat and Y.D. Zemenkov, 2002. Operation of the Main Gas Pipelines. 1st Edn., Publishing house "Vektor Buk", Tyumen, pp: 528.

Ivanov, V.A., V.V. Kochurova and Serebrennikov, 2003. A device for trenchless installation of polyethylene pipelines Russia RUS. Patent 223778321.01 .2003$.

Lavrov, I.G. and D. Serebrennikov, 2008. Experimental evaluation of the amount of deformation of polyethylene pipes in bending. Problems of operation of transport systems sourcebook AllRussian scientific-practical conference dedicated to the 45th anniversary of the founding of the Tyumen Industrial Institute, Leninskogokomsomola, Otvetstvennyyredaktor VI Bower.

Lavrov, I.G. and D. Serebrennikov, 2012. Analysis for the trenchless construction machinery and equipment polyethylene pipelines. Proceedings of the Problems of Functioning Transport System Materials of All-Russian Scientific-Practical Conference of Students, (PCS' 12), Graduate Students and Young Scientists, Tyumen, pp: 247-251.
Serebrennikov, A.A. and S.G. Kurochkin, 2003. The device for trenchless laying of pipelines of plastic/in the collection operation and maintenance of transport and technological machines. Interuniversity Collection of Scientific Papers, Tyumen.

Serebrennikov, A.A. and Z.R. Khakimov, 2012. The methodology and results of the determination of the resistance of the working body of the promotion of trenchless pipelayer. Scientific Techn. Gazette Volga, 6: 382-382.

Serebrennikov, D.A. and I.G. Lavrov, 2005. The methodology to determine the bending stresses of polyethylene pipelines experiment Interstroymeh. Proceedings of the International Scientific and Technical Conference, (STC' 05), Tyumen, pp: 130-134.

Serebrennikov, D.A., 2004. Justification machine operating parameters for trenchless installation of polyethylene pipelines: Dis. Cand. Tehn. Sciences. Tyumen.

Serebrennikov, D.A., I.G. Lavrov and Z.R. Khakimov, 2012. Using machines to plow working body in the construction of polyethylene pipelines. Proceedings of the Problems of Functioning of Transport Systems: Proceedings of All-Russian ScientificPractical Conference of Students, (PCS' 12), Graduate Students and Young scientists, Publishing House TSOGU, Tyumen, pp: 344-348. 